\title{
Helicobacter Genotyping and Detection in Peroperative Lavage Fluid in Patients with Perforated Peptic Ulcer
}

\author{
N. A. P. Komen • M. J. O. E. Bertleff • L. J. van Doorn • \\ J. F. Lange $\cdot$ P. W. de Graaf
}

Received: 6 July 2007 / Accepted: 12 August 2007 / Published online: 29 September 2007

(C) 2007 The Society for Surgery of the Alimentary Tract

\begin{abstract}
Introduction and Objectives Certain Helicobacter pylori genotypes are associated with peptic ulcer disease; however, little is known about associations between the H. pylori genotype and perforated peptic ulcer (PPU). The primary aim of this study was to evaluate which genotypes are present in patients with PPU and which genotype is dominant in this population. The secondary aim was to study the possibility of determining the H. pylori status in a way other than by biopsy.

Materials and Methods Serum samples, gastric tissue biopsies, lavage fluid, and fluid from the nasogastric tube were collected from patients operated upon for PPU. By means of PCR, DEIA, and LIPA the presence of the "cytotoxin associated gene" $(\operatorname{cag} A)$ and the genotype of the "vacuolating cytotoxin gene" were determined.

Results Fluid from the nasogastric tube was obtained from 25 patients, lavage fluid from 26 patients, serum samples from 20 patients and biopsies from 18 patients. Several genotypes were found, of which the vacA s1 $\operatorname{cag} A$ positive strains were predominant. Additionally, a correlation was found between the $H$. pylori presence in biopsy and its presence in lavage fluid $(p=0.015)$, rendering the latter as an alternative for biopsy. Sensitivity and specificity of lavage fluid analysis were $100 \%$ and $67 \%$, respectively.

Conclusion This study shows the vacA s1 $\operatorname{cag} A$ positive strain is predominant in a PPU population. The correlation found between the $H$. pylori presence in biopsy and its presence in lavage fluid suggests that analysis of the lavage fluid is sufficient to determine the $H$. pylori presence. Risks associated with biopsy taking may be avoided.
\end{abstract}

This work was presented at the 42nd Congress of the European Society for Surgical Research 2007, Rotterdam, The Netherlands, May $26^{\text {th }}, 2007$.

N. A. P. Komen $(\bowtie) \cdot$ J. F. Lange

Department of Surgery, Erasmus MC,

University Medical Center Rotterdam,

Rotterdam, The Netherlands

e-mail: n.komen@erasmusmc.nl

M. J. O. E. Bertleff

Department of Plastic Surgery, Diaconessenhuis Leiden,

Leiden, The Netherlands

L. J. van Doorn

Delft Diagnostic Laboratory,

Delft, The Netherlands

P. W. de Graaf

Department of Surgery, Reinier de Graaf Gasthuis,

Delft, The Netherlands
Keywords $H$. pylori . Perforated Peptic Ulcer - Genotype · Peroperative lavage fluid · Peptic Ulcer Disease

\section{Introduction}

Over the past decades the incidence of perforated peptic ulcer (PPU) has declined in the western world. However, with an incidence varying between two and 10 per 100,000, it still is a problem in modern society. ${ }^{1}$ Moreover, mortality rates caused by gastric and duodenal ulcer perforation vary between 10 and $40 \%$ and zero and $10 \%$ respectively, and is higher among elderly patients. ${ }^{2,3}$ Several risk factors for PPU have been described such as smoking, alcohol abuse, and history of peptic ulcer disease (PUD). ${ }^{2}$ However, the main pathogenic factors are considered to be the use of non-steroidal antiinflammatory drugs (NSAID) and the presence of H. pylori. ${ }^{2}$ 
Helicobacter pylori are widespread bacteria, with a prevalence ranging from $25 \%$ in the industrialized world to more than $70 \%$ in developing countries. ${ }^{4,5}$ Most infected people remain asymptomatic; however, a small group of carriers will develop PUD.

Of patients who have developed PPU, 70\% will test positive for $H$. pylori, ${ }^{2}$ suggesting the pathogenesis of perforation is associated with the presence of $H$. pylori. In addition, it is shown that different genotypes of $H$. pylori are associated with different clinical manifestations like PUD and gastric cancer. 6,7 Two well-known H. pylori genes that have been associated with PUD are the cytotoxinassociated gene $(\operatorname{cag} A)$ and the vacuolating cytotoxin gene (vacA). ${ }^{6,8-10}$

VacA is present in all H. pylori strains and is associated with gastritis, PUD, and gastric carcinoma. ${ }^{10-12}$ It encodes for a vacuolating cytotoxin that causes epithelial cell injury and interferes with the immune system. ${ }^{13,14}$ VacA contains at least two variable regions, the signal peptide (s)-region and the middle (m)-region. The s-region contains two allelic types, s1 and s2. The s1 strain has several subtypes, being s1a, s1b, and s1c. ${ }^{15}$ Two allelic types exist for the $\mathrm{m}$-region, $\mathrm{m} 1$ and $\mathrm{m} 2$. The latter has two subtypes, $\mathrm{m} 2 \mathrm{a}$ and $\mathrm{m} 2 \mathrm{~b} .{ }^{16}$

$\operatorname{Cag} A$ is considered a marker for a genomic pathogenicity (cag) island that is associated with enhanced virulence. ${ }^{17}$

If PPU is associated with a specific $H$. pylori genotype it may be feasible to limit the patients undergoing antibiotic therapy to those who have this genotype. When this specific type is not present, another cause of PPU should be looked for and antibiotic therapy should not be started. This would mean cost reduction and, probably, a reduction in the speed of the development of antibiotic resistance.

Currently, gastric biopsy during endoscopy is a generally accepted method to diagnose $H$. pylori infection. However, patients with PPU will not undergo endoscopy but will generally be operated upon immediately. Taking a biopsy intraoperatively implicates a higher risk of bleeding and more difficult closure of the defect. Therefore, surgeons are reluctant to take a biopsy.

The primary aim of this study was to evaluate which genotypes are present in patients with PPU and if a genotype is dominant in this population. The secondary aim was to study the possibility of determining the $H$. pylori status in a manner other than by gastric tissue biopsy.

\section{Methods}

From 30 consecutive patients operated on for PPU serum samples, gastric tissue biopsies, lavage fluid, and fluid from the nasogastric tube were collected. These patients were treated in five different medical centers throughout the
Netherlands. In each of these centers approval of the medical ethical committee was obtained. Immediately after collection, the materials were frozen at $-20^{\circ} \mathrm{C}$. One researcher performed the analysis and genotyping. For $H$. pylori genotyping, the presence of cytotoxin-associated gene $(\operatorname{cag} A)$ and the s- and m-region genotypes of the vacuolating cytotoxin gene (vacA) were determined.

DNA was isolated according to Boom's method as described previously. ${ }^{18}$ A guanidine thiocyanate (GuSCN) solution was added to the collected material to induce lysis of the bacteria, releasing their DNA. After addition of the silica particles (Celite) the suspension was centrifuged. The silica particles, with the attached DNA, were washed with subsequently GuSCN-containing washing buffer, ethanol $70 \%$ and acetone. After drying, the DNA was eluted in an aqueous low salt buffer. The isolated DNA was amplified by means of polymerase chain reaction (PCR) and subsequently the presence of $\operatorname{cag} A$ and different types of $v a c A$ were analyzed by means of reverse hybridization on a strip (32). This assay consists of a nitrocellulose strip that contains dT-tailed oligonucleotide probes immobilized as parallel lines. For each strain, $10 \mu \mathrm{l}$ of each PCR product (containing biotin at the $5^{\prime}$ end of each primer) was denatured by the addition of an equal amount of $400 \mathrm{mM}$ $\mathrm{NaOH}$ and $10 \mathrm{mM}$ EDTA in a plastic trough. After $5 \mathrm{~min}$, $1 \mathrm{ml}$ of prewarmed hybridization solution $(2 \times \mathrm{SSC}[1 \times \mathrm{SSC}$ is $0.15 \mathrm{M} \mathrm{NaCl}$ plus $0.015 \mathrm{M}$ sodium citrate], $50 \mathrm{mM}$ Tris$\mathrm{HCl}$ [pH 7.5], 0.1\% SDS) was added, and a strip was submerged and incubated in a shaking water bath at $50^{\circ} \mathrm{C}$ for $1 \mathrm{~h}$. The strips were washed with $2 \mathrm{ml}$ of $2 \times \mathrm{SSC}-0.1 \%$ SDS for $30 \mathrm{~min}$ at $50^{\circ} \mathrm{C}$. Subsequently, the strips were rinsed three times in phosphate buffer, and conjugate (streptavidin-alkaline phosphatase) was added. After incubation at room temperature for $30 \mathrm{~min}$, the strips were rinsed again and 4-nitroblue tetrazolium chloride and 5-bromo-4-chloro-3-indolylphosphate substrate was added. Hybrids are visible as purple probe lines. Interpretation of the hybridization patterns was performed visually. As a control, a $\beta$-globin PCR was performed. Patient related factors were obtained prospectively. Statistical analysis was performed with SPSS for Windows, version 11.0.

\section{Results}

A total of 30 patients were included of whom nine were women. The average age was 65 years, varying between 40 and 87 . Ten patients $(33.3 \%)$ were operated laparoscopically. The perforation was found prepyloric in 11 patients, at the site of the pylorus in eight patients and postpyloric in 11 patients.

A total of five (16.7\%) patients had a history of PUD. Ten patients $(33.3 \%)$ used NSAID's, two patients $(6.7 \%)$ 
Table 1 Helicobacter pylori Status and Genotype

\begin{tabular}{|c|c|c|c|c|}
\hline Patient & $\begin{array}{c}\text { Fluid from } \\
\text { naso-gastric } \\
\text { tube }\end{array}$ & Lavage fluid & Serum & $\begin{array}{c}\text { Gastric tissue } \\
\text { biopsy }\end{array}$ \\
\hline 1 & s1a/m2a/cag & & & \\
\hline 2 & s1a/m2a/cag & s1a/m2a/cag & & s1a/m2a/cag \\
\hline 3 & $\mathrm{~s} 1 \mathrm{~b}$ & s1a/m2a/cag & & \\
\hline 4 & & $\mathrm{~s} 1 \mathrm{a} / \mathrm{s} 2 / \mathrm{m} 2 \mathrm{a}$ & & \\
\hline 5 & & s1a & & $\mathrm{s} 1 \mathrm{a} / \mathrm{m} 1$ \\
\hline \multicolumn{5}{|l|}{6} \\
\hline 7 & $\mathrm{~s} 1 \mathrm{a} / \mathrm{m} 2 \mathrm{a}$ & & & \\
\hline \multicolumn{5}{|l|}{8} \\
\hline 9 & $\mathrm{~s} 1 \mathrm{~b} / \mathrm{m} 1 / \mathrm{cag}$ & $\mathrm{s} 1 \mathrm{~b} / \mathrm{m} 1 / \mathrm{cag}$ & & \\
\hline \multicolumn{5}{|l|}{10} \\
\hline \multicolumn{5}{|l|}{11} \\
\hline 12 & & s1a/m2a/cag & & \\
\hline \multicolumn{5}{|l|}{13} \\
\hline 14 & s1a/m1/cag & & & s1a/m1/cag \\
\hline 15 & & $\mathrm{~s} 1 \mathrm{a} / \mathrm{m} 1 / \mathrm{cag}$ & & s1a \\
\hline 16 & s1a/m1/cag & $\mathrm{s} 1 \mathrm{a} / \mathrm{m} 1 / \mathrm{cag}$ & & \\
\hline 17 & s1a/m1/cag & & & \\
\hline \multicolumn{5}{|l|}{18} \\
\hline 19 & s1a/m1/cag & s1a/m1/cag & & \\
\hline 20 & s1a/m1/cag & s1a/m1/cag & & \\
\hline 21 & s1a/m1/cag & $\mathrm{s} 1 \mathrm{a} / \mathrm{m} 1 / \mathrm{cag}$ & & \\
\hline \multicolumn{5}{|l|}{22} \\
\hline 23 & & s1a/m1/cag & & \\
\hline 24 & s1a/s1b/m1/cag & $\mathrm{s} 1 \mathrm{a} / \mathrm{s} 1 \mathrm{~b} / \mathrm{m} 1 / \mathrm{cag}$ & & $\mathrm{s} 1 \mathrm{~b} / \mathrm{m} 1$ \\
\hline 25 & & s1a/m1/cag & & $\mathrm{s} 1 \mathrm{~b} / \mathrm{m} 1 / \mathrm{cag}$ \\
\hline 26 & & s1a/m2a/cag & & \\
\hline 27 & & $\mathrm{~s} 1 \mathrm{a} / \mathrm{m} 2 \mathrm{a}$ & & s1a/m1/cag \\
\hline 28 & s1a/s $2 / \mathrm{m} 2 \mathrm{a} / \mathrm{cag}$ & $\mathrm{s} 1 \mathrm{a} / \mathrm{s} 2 / \mathrm{m} 2 \mathrm{a} / \mathrm{cag}$ & & $\mathrm{s} 1 \mathrm{a} / \mathrm{s} 2 / \mathrm{m} 2 \mathrm{a} / \mathrm{cag}$ \\
\hline 29 & & $s 2 / m 2 a$ & & $s 2 / m 2 a$ \\
\hline \multicolumn{5}{|l|}{30} \\
\hline & \multicolumn{4}{|c|}{ B-globin and $H$. pylori positive } \\
\hline & \multicolumn{4}{|c|}{ B-globin and $H$. pylori negative } \\
\hline & \multicolumn{4}{|c|}{ B-globin positive and $H$. pylori negative } \\
\hline & \multicolumn{4}{|c|}{ B-globin negative and $H$. pylori positive } \\
\hline & \multicolumn{4}{|c|}{ No materials } \\
\hline
\end{tabular}

The colors represent the $\beta$-globin and H. pylori status of the patient.

used steroids, three patients (10.0\%) used acid reducers, and one patient (3.3\%) used a proton pump inhibitor (PPI) before admission to the hospital. The average hospital stay was 11.9 days, varying between 3 and 37 days.

Fluid from the nasogastric tube was obtained from 25 patients, lavage fluid from 26 patients, serum samples from 20 patients, and ulcer biopsies from 18 patients. The results of the genotyping are depicted in Table 1.

The $\beta$-globin determination was performed as a control. In nine samples of nasogastric tube fluid and in two samples of lavage fluid it was negative, rendering these results as unreliable. Therefore, these results were excluded from further analysis.

Table 2 represents the frequency of the individual genes and the allelic types found in the different samples by means of PCR and LiPA.

These tables show that for vacA the allelic type s1 is predominantly present in all three types of samples. In the s1 positive strains, subtype s1a is predominant as depicted in Table 3.

With regard to the middle region of vacA the incidence of $\mathrm{m} 1$ allelic type is slightly higher; however, the difference 
Table 2 Frequencies of Individual Genes and Allelic Types

\begin{tabular}{|c|c|c|c|c|c|c|c|}
\hline \multirow[t]{2}{*}{ Genotype } & \multicolumn{2}{|c|}{ Fluid from Naso-Gastric Tube } & \multicolumn{2}{|c|}{ Lavage Fluid } & \multicolumn{2}{|c|}{ Gastric Tissue Biopsy } & \multirow{2}{*}{$\begin{array}{l}\text { Control Non-Ulcer } \\
\%\end{array}$} \\
\hline & No. & $\%$ & No. & $\%$ & No. & $\%$ & \\
\hline $\operatorname{Vac} A \mathrm{~s} 1$ & 10 & 90.9 & 14 & 77.8 & 7 & 77.8 & 46.9 \\
\hline $\operatorname{Vac} A \mathrm{~s} 2$ & 0 & 0 & 1 & 5.5 & 1 & 11.1 & 38.4 \\
\hline VacA multiple & 1 & 9.1 & 3 & 16.7 & 1 & 11.1 & 14.7 \\
\hline Total & 11 & 100 & 18 & 100 & 9 & 100 & 100 \\
\hline $\operatorname{Vac} A \mathrm{~m} 1$ & 6 & 54.5 & 9 & 50.0 & 5 & 55.6 & 29.4 \\
\hline VacA $\mathrm{m} 2$ & 4 & 36.4 & 8 & 44.4 & 3 & 33.3 & 55.9 \\
\hline VacA incomplete genotype & 1 & 9.1 & 1 & 5.6 & 1 & 11.1 & 0 (14.7\% incomplete $)$ \\
\hline Total & 11 & 100 & 18 & 100 & 9 & 100 & 100 \\
\hline CagA positive & 9 & 81.8 & 14 & 77.8 & 5 & 55.6 & 47.1 \\
\hline Total & 11 & 100 & 18 & 100 & 9 & 100 & 100 \\
\hline
\end{tabular}

"VacA multiple" means that more than one allelic type or subtype has been found in one sample.

In each different type of sample one incomplete genotype occurred, which is indicated as "vacA incomplete". The "Control non ulcer" column represents the frequencies, found by van Doorn et al., in a population without PUD and is added to allow easy comparison.

is less outspoken compared to s1. The m2a was the only subtype that was found in the samples. In three samples, the genotyping was incomplete (Tables 1 and 2), meaning that determination of the middle region was not possible. This was most likely caused by the small number of bacteria present in those samples.

With regard to the secondary aim of this study, analyzing possibilities to diagnose $H$. pylori presence in another fashion than through biopsy, the H. pylori status found in each type of sample was compared. A correlation was found between the $H$. pylori presence in biopsy and its presence in lavage fluid (Fisher's exact test, $p=0.015$ ), indicating lavage fluid is a valid alternative for determination of $H$. pylori infection.

The sensitivity and specificity of the lavage fluid analysis was calculated, considering biopsy as a golden standard. Fourteen patients, of which the lavage fluid as well as the biopsy was analyzed, were included into this calculation (patients $2,4,5,6,8,10,15,23-25,27-30$, Table 1), which is shown in Table 4. Of the remaining patients, either the biopsy or the lavage fluid was missing; therefore, these data cannot be used in the sensitivity/ specificity calculation.

The sensitivity was $100 \%$, which means that in case of the presence of $H$. pylori in the biopsy specimen, the lavage fluid analysis detected it in $100 \%$ of cases. The specificity of lavage fluid analysis was $66.7 \%$, which means the chance for false-positives is over $30 \%$. With regard to gender, age, BMI, history of PUD, location of perforation, complications after procedure, and use of steroids, PPI, or antihistaminic medication, no statistically significant correlation was found.

\section{Discussion}

Concerning the role of $H$. pylori in the pathogenesis of PPU, some studies have been reported comparing the prevalence of $H$. pylori infection in patients with PPU to the prevalence in controls. They appear to be similar, suggesting that other factors like NSAID use play a role. ${ }^{19-21}$ However, the substantial genetic heterogeneity

Table 3 Distribution of the vacA s1 Subtypes

\begin{tabular}{|c|c|c|c|c|c|c|c|}
\hline \multirow[t]{2}{*}{ VacA Subtype } & \multicolumn{2}{|c|}{ Fluid from Naso-Gastric Tube } & \multicolumn{2}{|c|}{ Lavage Fluid } & \multicolumn{2}{|c|}{ Gastric Tissue Biopsy } & \multirow{2}{*}{$\begin{array}{l}\text { Control Non-Ulcer } \\
\%\end{array}$} \\
\hline & No. & $\%$ & No. & $\%$ & No. & $\%$ & \\
\hline S1a & 8 & 80.0 & 13 & 92.9 & 5 & 71.4 & 81.3 \\
\hline $\mathrm{S} 1 \mathrm{~b}$ & 2 & 20.0 & 1 & 7.1 & 2 & 28.6 & 18.7 \\
\hline S1c & 0 & 0 & 0 & 0 & 0 & 0 & 0 \\
\hline Total & 10 & 100 & 14 & 100 & 7 & 100 & 100 \\
\hline
\end{tabular}

The sla subtype is predominant in all sample types.

The "Control non ulcer" column represents the frequencies, found by van Doorn et al., in a population without PUD and is added to allow easy comparison. 
Table 4 Calculation of Sensitivity and Specificity of Lavage Fluid Analysis

\begin{tabular}{lllll}
\hline & Biopsy & & & \\
\hline Lavage fluid & & + & - & Total \\
& + & 8 & 2 & 10 \\
& - & 0 & 4 & 4 \\
& Total & 8 & 6 & 14 \\
& & Sens $8 / 8=1$ & Spec $4 / 6=0.67$ & \\
\hline
\end{tabular}

of H. pylori that has been revealed over the years leads to the hypothesis of a specific genotype causing PPU. ${ }^{5}$ Controls might test positive for $H$. pylori, but not develop PPU because it would not be this specific genotype that is isolated. This study of a selected population of patients, all with PPU, shows a limited diversity of $H$. pylori genotypes as represented by Table 1 .

VacA s1 strains are predominantly present in the three sample types of which sla is the predominant subtype. Concerning the vacA m-region, the $\mathrm{m} 1$ strains are found in a majority of cases; however, the difference is less convincing than for vacA s1. Except for the biopsy samples, the $\operatorname{cag} A$ positive strains were predominantly present is this population. In the biopsy samples, the frequency of $\operatorname{cag} A$ positive strains seemed to be low; however, this number is distorted because in two of nine positive biopsies, a decent comparison with the other samples was not possible. In patient 5 , genotyping of the lavage fluid and nasogastric tube fluid was incomplete, and for patient 15 , the opposite was the case. This means that the actual incidence should be $71.4 \%(5 / 7)$.

Summarising, these results shows that the vacA s1, $\operatorname{cag} A$-positive strains were predominant in this population of patients with PPU. This finding is in accordance with literature reporting correlations between the presence of vacA s1, cagA-positive strains and PUD. ${ }^{6,10}$ Therefore, detection of the genotype $v a c A$ s1 does not specifically predict PPU; nevertheless, clinicians should be aware of this association.

In Tables 2 and 3 the genetic distribution in a Dutch population without PUD, as found by van Doorn et al., are added for comparison. The frequencies found in this study for vacA s1, $\mathrm{m} 1$, and $\operatorname{cag} A$-positive strains are clearly higher than in the non-PUD group, confirming the aforementioned hypothesis. However, with regard to the subtypes, Table 3 shows an almost similar distribution of frequencies, suggesting that determination of the allelic subtype is of less importance.

In only $60 \%$ of patients biopsies could be analyzed. The reason for missing $40 \%$ is the restraint of the surgeon to take a biopsy when risk of bleeding and more difficult closure of the defect was estimated to be too high, which emphasizes the importance of finding an alternative. To do so, the $H$. pylori status of the patient as determined by biopsy was compared to the status as determined by analysis of nasogastric tube fluid, lavage fluid, and serum. A statistically significant correlation was found between the H. pylori status in biopsy and its status in lavage fluid (Fisher's exact test, $p=0.015$ ). This finding suggests that determination of the $H$. pylori status can be done with lavage fluid as well, obviously without any risk of bleeding and closure related difficulties. The sensitivity is $100 \%$, but the specificity is $66.7 \%$. This could mean the chance for false-positives is over $30 \%$, which is not optimal and could lead to therapy overshoot. However, considering the fact that with the lavage a larger area is sampled, rendering the chance of positive test results higher than in biopsy, it is more likely to find false negative biopsy results. This could lead to a therapy undershoot, which obviates the importance having an alternative for a biopsy.

In only two samples, both nasogastric tube fluids, a $H$. pylori genotype was isolated, while $\beta$-globin tested negative. In nine samples (seven nasogastric tube fluid, two lavage fluid) both $\beta$-globin and $H$. pylori tested negative. This means that either no humane cells were present in the samples, which is unlikely, or that an error in the PCR procedure had occurred. Because this was unclear these results were considered unreliable. Therefore, it still could be possible that nasogastric tube fluid is a good alternative for determining the $H$. pylori status as well.

Overall, these results are positive, however they should be confirmed in a larger population.

\section{Conclusion}

This study shows that in a population of 30 patients with PPU, vacA s1, cagA positive strains are predominant. This finding is in accordance with literature reporting correlations between the presence of vacA s1, cagA-positive strains, and PUD. Therefore, detection of this genotype does not specifically predict PPU. Nevertheless, clinicians should be aware of this association.

This study shows as well that it is feasible to use intraoperative lavage fluid to determine the $H$. pylori status of the patient, implicating that biopsies, with a risk of bleeding and more difficult closure of the defect, are not necessary anymore. In addition, considering the fact that a larger area is sampled with lavaging, biopsies may result in more false negative results leading to insufficient therapy.

Acknowledgments The authors would like to thank W.A. Bemelman (Department of Surgery, University of Amsterdam, Amsterdam, The Netherlands), A. van der Ham (Department of Surgery, Sint Franciscus Gasthuis, Rotterdam, The Netherlands), I. Oei (Department of Surgery, Reinier de Graaf Gasthuis, Delft, The Netherlands), and Bianca Gieze (Crucell, Leiden, The Netherlands) for their input in this study. 


\section{References}

1. Higham J, Kang JY, Majeed A. Recent trends in admissions and mortality due to peptic ulcer in England: Increasing frequency of haemorrhage among older subjects. Gut 2002;50:460-464.

2. Gisbert JP, Pajares JM. Helicobacter pylori infection and perforated peptic ulcer prevalence of the infection and role of antimicrobial treatment. Helicobacter 2003;8:159-167.

3. Sarosi GA Jr, Jaiswal KR, Nwariaku FE, Asolati M, Fleming JB, Anthony T. Surgical therapy of peptic ulcers in the 21 st century: More common than you think. Am J Surg 2005;190:775-779.

4. Holcombe C, Omotara BA, Eldridge J, Jones DM. H. pylori, the most common bacterial infection in Africa: A random serological study. Am J Gastroenterol 1992;87:28-30.

5. van Doorn LJ. Detection of Helicobacter pylori virulenceassociated genes. Exp Rev Mol Diagn 2001;1:290-298.

6. Erzin Y, Koksal V, Altun S, Dobrucali A, Aslan M, Erdamar S, Dirican A, Kocazeybek B. Prevalence of Helicobacter pylori vacA, cagA, cagE, iceA, babA2 genotypes and correlation with clinical outcome in Turkish patients with dyspepsia. Helicobacter 2006;11:574-580.

7. Tham KT, Peek RM Jr, Atherton JC, Cover TL, Perez-Perez GI, Shyr Y, Blaser MJ. Helicobacter pylori genotypes, host factors, and gastric mucosal histopathology in peptic ulcer disease. Hum Pathol 2001;32:264-273.

8. Atherton JC. H. pylori virulence factors. Br Med Bull 1998;54: $105-120$.

9. Chen XJ, Yan J, Shen YF. Dominant cagA/vacA genotypes and coinfection frequency of $\mathrm{H}$. pylori in peptic ulcer or chronic gastritis patients in Zhejiang Province and correlations among different genotypes, coinfection and severity of the diseases. Chin Med J (Engl) 2005;118:460-467.

10. van Doorn LJ, Figueiredo C, Sanna R, Plaisier A, Schneeberger P, de Boer W, Quint W. Clinical relevance of the cagA, vacA, and iceA status of Helicobacter pylori. Gastroenterology 1998;115:58-66.

11. Marshall BJ, Warren JR. Unidentified curved bacilli in the stomach of patients with gastritis and peptic ulceration. Lancet 1984;1:1311-1315.
12. Parsonnet J, Hansen S, Rodriguez L, Gelb AB, Warnke RA, Jellum E, Orentreich N, Vogelman JH, Friedman GD. Helicobacter pylori infection and gastric lymphoma. N Engl J Med 1994;330:1267-1271.

13. Sundrud MS, Torres VJ, Unutmaz D, Cover TL. Inhibition of primary human $\mathrm{T}$ cell proliferation by Helicobacter pylori vacuolating toxin (VacA) is independent of VacA effects on IL-2 secretion. Proc Natl Acad Sci USA 2004;101:7727-7732.

14. Yamasaki E, Wada A, Kumatori A, Nakagawa I, Funao J, Nakayama M, Hisatsune J, Kimura M, Moss J, Hirayama T. Helicobacter pylori vacuolating cytotoxin induces activation of the proapoptotic proteins Bax and Bak, leading to cytochrome $\mathrm{c}$ release and cell death, independent of vacuolation. J Biol Chem 2006;281:11250-11259.

15. van Doorn LJ, Figueiredo C, Sanna R, Pena S, Midolo P, Ng EK, Atherton JC, Blaser MJ, Quint WG. Expanding allelic diversity of Helicobacter pylori vacA. J Clin Microbiol 1998;36:2597-2603.

16. Atherton JC, Cao P, Peek RM Jr, Tummuru MK, Blaser MJ, Cover TL. Mosaicism in vacuolating cytotoxin alleles of Helicobacter pylori. Association of specific vacA types with cytotoxin production and peptic ulceration. J Biol Chem 1995;270: 17771-17777.

17. van Doorn LJ, Schneeberger PM, Nouhan N, Plaisier AP, Quint WG, de Boer WA. Importance of Helicobacter pylori cagA and vacA status for the efficacy of antibiotic treatment. Gut 2000;46: 321-326.

18. Boom R, Sol CJ, Salimans MM, Jansen CL, Wertheim-van Dillen PM, van der Noordaa J. Rapid and simple method for purification of nucleic acids. J Clin Microbiol 1990;28:495-503.

19. Kate V, Ananthakrishnan N, Badrinath S. Effect of Helicobacter pylori eradication on the ulcer recurrence rate after simple closure of perforated duodenal ulcer: retrospective and prospective randomized controlled studies. Br J Surg 2001;88:1054-1058.

20. Lanas A, Serrano P, Bajador E, Esteva F, Benito R, Sainz R. Evidence of aspirin use in both upper and lower gastrointestinal perforation. Gastroenterology 1997;112:683-689.

21. Reinbach DH, Cruickshank G, McColl KE. Acute perforated duodenal ulcer is not associated with Helicobacter pylori infection. Gut 1993;34:1344-1347. 